\title{
Power Cable Structure Recovery and Application Based on Mould Melt Joint
}

\author{
Haijie Zhong ${ }^{1, a^{*}}$, Yunjie Xia ${ }^{1, b}$, Jinming Wang ${ }^{1, c}$, Hong Huang ${ }^{1, d}$ and Zhenjie \\ Liang ${ }^{1,}$ e \\ ${ }^{1}$ CYG Electric Technology Co., Ltd., 519085 Zhuhai, China \\ azhjcydl@126.com, bxyjcydl@126.com, ‘wjmcydl@126.com, dhypmm2006@163.com, \\ e1465127625@qq.com
}

\begin{abstract}
Keywords: mould melt joint, power cable, structure recovery.
Abstract. Many failures of power cable system expose that power cable accessories are the main weak point because of frequently poor workmanship and low-quality when installed on-site. That introduces a question that could we use another method to reduce power cable accessories failures rate. Mould Melt Joint (MMJ) is the new method to fully restore original cable body structure on the cable joints in the field, so that the electrical properties of the connection of cable and MMJ and the cable body equalization reach a high-security state. The technique has obvious technical advantages compared with traditional power cable joint. MMJ specification is almost equal to power cable outer diameter, which will occupy less space than traditional power cable accessories and could be applied in occasion such as sinuosity and high-altitude. Mould Melt Joint has been applied in many occasions with good effect, indicating a good application prospect.
\end{abstract}

\section{Introduction}

As we all know, the power cable system consists of power cable and its accessories, which is a world-wide accepted mode for power cable industry. The manufacture technology for power cable is fully developed, which has explicit demand for insulation material type, insulation thickness etc. Meanwhile, insulation material and insulation thickness for power cable accessories present diversification, such as silicone rubber and ethylene-propylene rubber. This paper presents a new Power Cable Structure Recovery named Mould Melt Joint (MMJ).

Generally speaking, electric field in power cable accessories distributes more complicated than that in power cable [1]. Consequently, power cable system reliability mainly depends on power cable accessories that form the main weak point of the whole power cable system. That results in many failures such as HV and EHV power cable accessories. The cause consists in the fact that the accessories workmanship and quality. Mould Melt Joint (MMJ) is a new method to ensure Power Cable Structure on site. This technology will provide strong support for realizing safe, reliable and efficient operation of the power cable system, cutting down failures rate and AC and DC flexible joint for marine cable, which has certain value in practice.

\section{Power Cable Structure Recovery Method}

\subsection{Definitions}

MMJ is the abbreviation of mould melt joint, mainly used in the MMJ middle connection of MV, HV and EHV XLPE insulated power cable, such as $10 \mathrm{kV}, 20 \mathrm{kV}, 35 \mathrm{kV}, 66 \mathrm{kV}, 110 \mathrm{kV}, 132 \mathrm{kV}, 220 \mathrm{kV}$, $500 \mathrm{kV}$, and also DC submarine cables, the voltages is $160 \mathrm{kV}, 200 \mathrm{kV}, 320 \mathrm{kV}$ and $400 \mathrm{kV}$. For the accidentally destroyed cable in the running or lying, MMJ techniques can also repair the cable.

\subsection{Design Principles}

For the high voltage cables, the cable is produced according to the corresponding standards, specifications given in accordance with the design and stability of the production process [2]. The safety and reliability of the cable in actual application process is much higher than the cable accessories connected together. Taking the structural principles into account, the cable body is consisted of the same thickness of the insulating layer, the inner and outer semi-conductive layer, the 
same diameter of the conductor. It is a solid cylindrical cable body. Therefore, the ordered structure of cable makes the electrical properties, the electric field distribution more stable and uniform. The cable has a higher electrical safety and reliability and a longer service life. And MMJ based on this principle, can fully restore original cable body structure on the cable joints in the field, so that the electrical properties of the connection of cable and MMJ and the cable body equalization reach a high-security state. The cable conductor, inner semi-conductive layer, the primary insulation and outer semi-conductive layer on the MMJ joints will fully recover the cable body in accordance with the original structure of the cable. There is no stress cone assembly structure. So the cable connections become complete cable without cable joins.

The MMJ production material is exactly the same with the production of semi-conductive material and insulation materials of the cable. So the connection of the cable and MMJ has good blending and stability on the chemical properties, physical properties and structure [3]. The thermal properties and mechanical properties of the melt interface both fully meet the standard requirements, which are tested by a large number of experiments. MMJ also reflects its superior practicality in the running process.

\subsection{Design Features}

Features of MMJ are the same with HV and EHV XLPE cable. The electrical properties need high safety and reliability. MMJ production technology and production process is different from the cable link, but the realization principles and the standard of production processes are consistent. The insulation level, carrying capacity, mechanical properties and sealing performances of MMJ must fully meet the requirements of the cable. And also ensure the long-term safe operation in harsh environments, full compliance with the relevant national standards. MMJ can also be made into a overall connection with a equally same diameter of the cable insulation according to the different needs of users. Such as submarine cable connector requires a same diameter with the connecting cable. The structural form of MMJ is the same with the cable, no activity objects equipped, and there are insulation joints and straight joints distinction in order to achieve cross-connects.

\subsection{Production requirements}

MMJ production is completed after the cable lying in the field. The technical staff is professional full-time production technician, and must undergo a rigorous training of MMJ. The MMJ production environment is the same with the traditional cable accessories installation, no special requirements [4]. A key part needs a clean environment, the professional and technical personnel use the supporting the positive carry-conditioned clean studio, anti-static clean clothes, pollution dedicated hood, gloves, anti-pollution devices and tooling to control the process and ensure a clean environment.

\section{Advantage of MMJ technology}

\subsection{Advantage of structure design}

MMJ is should not be classified as power cable accessories. It is re-produced as a power cable combination without stress cone and interface between insulation of melt-structure (shown in Fig.1). The electrical field distribution and electric consistency in MMJ is in accord with that of power cable, which has high reliability advantage. As MMJ specification is almost equal to power cable outer diameter. That will occupy less space than traditional power cable accessories and could be applied in occasion such as sinuosity and high-altitude, which has an example in a overhead steel tower with swerved mode for an recovered power cable failure.

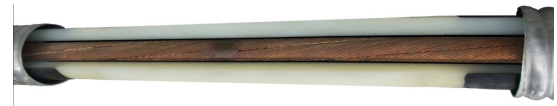

(a) profile map of MMJ equant insulation recovery 


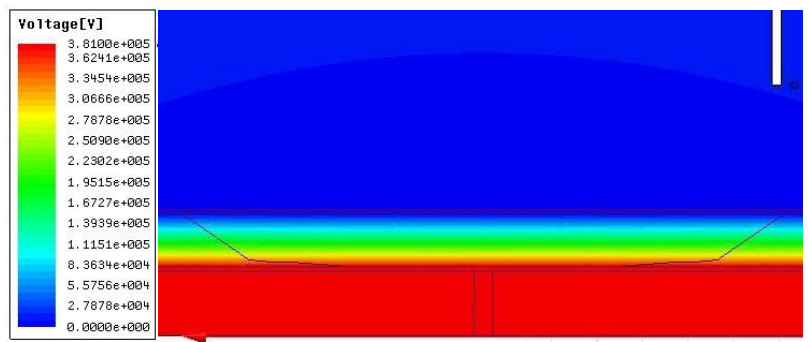

(b) electrical field distribution map of MMJ

Fig.1 Profile map of MMJ equant insulation recovery and electrical field distribution

\subsection{Advantage of material}

The insulation and semiconducting material of $\mathrm{MMJ}$ is the same as that in power cable factory, which is the biggest difference from traditional power cable accessories. The insulation and semiconducting material are totally-enclosed in Super Clean Workshop with $15-25^{\circ} \mathrm{C}$ temperature range. When used, professional staff operates and load to packing canister and keep closed for next time [5].

\subsection{Advantage of workmanship standard}

All the design guarantee figures and parameters are fixed when MMJ are manufacturing. In order to ensure the demand of micro-cavity, impurity, dimension, interface embossment and degree of crosslinking, the process of manufacture is realized as same as power cable. That means MMJ manufacture is carried out the same standard and criterion as power cable. MMJ structure is the same as power cable structure. The interface between out-semiconducting layer and inner- semiconducting layer cannot be peeled off, leading effect as three-layer coextrusion process.

\subsection{Physical properties of Practical Measurement}

Tab.1 shows the Measurement result of interface between MMJ insulation and main insulation, which meet the requirements of standards. Obviously, MMJ needs control stability to remove human element using program controlling. Moreover, detection method after installation is essential to on-site installation. Insulation between MMJ and power cable insulation is Molecular -permeation level without air gap, which differs from conventional power cable accessories.

Tab.1 Measurement result of interface between MMJ insulation and main insulation

\begin{tabular}{|c|c|c|c|c|}
\hline Test Item & Unit & $\begin{array}{l}\text { Requirements } \\
\text { of standards }\end{array}$ & $\begin{array}{l}\text { Measurement } \\
\text { results }\end{array}$ & Evaluation \\
\hline $\begin{array}{l}1 \text { Physical mechanical performance } \\
\text { before and after ageing } \\
\text { 1) Before aging } \\
\text { - Tensile strength }\end{array}$ & $\mathrm{N} / \mathrm{mm}^{2}$ & $\geq 12.5$ & 19.7 & pass \\
\hline —Breaking strength & $\%$ & $\geq 200$ & 560 & pass \\
\hline $\begin{array}{l}\text { 2) After ageing }\left(135^{\circ} \mathrm{C}, 7 \mathrm{~d}\right) \\
\text { - Rate of Change of tensile strength }\end{array}$ & $\%$ & \pm 25 & 5.6 & pass \\
\hline $\begin{array}{l}\text { - Rate of Change of tensile strength } \\
\text { breaking strength }\end{array}$ & $\%$ & \pm 25 & 4.2 & pass \\
\hline $\begin{array}{l}2 \text { Insulation heat stretch test }\left(200{ }^{\circ} \mathrm{C}\right) \\
\text { 1) Elongation }\left(\mathrm{Load} 20 \mathrm{~N} / \mathrm{cm}^{2}, 15 \mathrm{~min}\right)\end{array}$ & $\%$ & $\leq 175$ & 80 & pass \\
\hline 2) Permanent tension after cooling & $\%$ & $\leq 15$ & 6 & pass \\
\hline $\begin{array}{l}3 \text { Insulation micro-cavity and impurity } \\
\text { detection } \\
\text { 1) Larger than } 0.05 \mathrm{~mm}\end{array}$ & No. & 0 & 0 & pass \\
\hline 2) $0.025 \mathrm{~mm} \sim 0.05 \mathrm{~mm}$ & No. $/ 16.4 \mathrm{~cm}^{3}$ & $\leq 30$ & 18 & pass \\
\hline
\end{tabular}




\subsection{Advantage of Wide Application}

As MMJ has advantage such as quick on-site installation, electrical stabilization, good yieldingness and Small volume, it is more and more widely used in failure recovery needing short time. Up to now, MMJ technology has many cases in the power company, such as $220 \mathrm{kV} / 500 \mathrm{~mm}^{2}, 110 \mathrm{kV} / 800 \mathrm{~mm}^{2}$, $110 \mathrm{kV} / 630 \mathrm{~mm}^{2}$, etc.

\section{Installation Flow}

The Installation Flow of MMJ is shown in Fig.2.

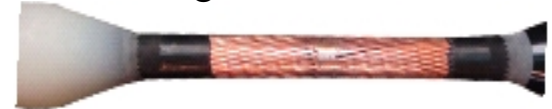

(a) conductor junction of Equal Diameter

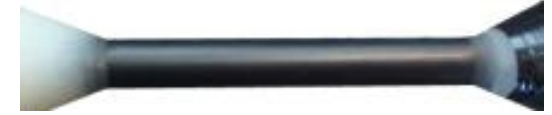

(b) inner semi-conductor recovery of Equal Diameter

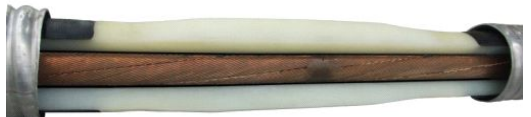

(c) insulation recovery of Mould melt

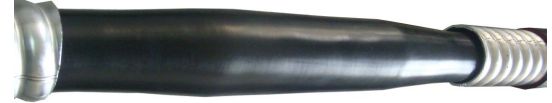

(d) outer semi-conductor recovery

Fig.2 The installation flow of MMJ

\section{Cases}

Fig.3 shows some cases in power company. which has good operation effect since used.
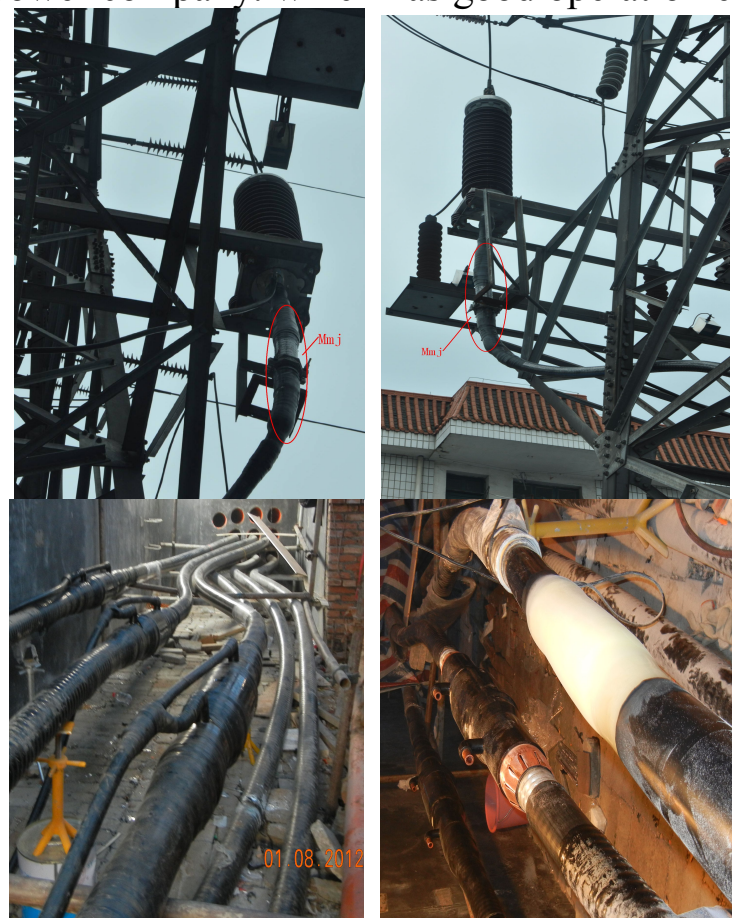

Fig.3 Application cases of MMJ

\section{Conclusions}

At present, some of the power cable line are operating with defect because of poor workmanship, especially in power cable accessories. Mould Melt Joint (MMJ) technology meets the 
demand to quickly recovering the failure power cable using a new method,indicating a good application prospect.

\section{References}

[1] CIGRE TB 219-2003, Recommendation Test standard of DC extruded power cable system of rated up to $250 \mathrm{kV}$.

[2] Zhuo Jinyu, Design principle of power cable. China Machine Press, 1999.

[3] Tony Blythe, David Bloor. Electrical Properties of Polymers. Cambridge University Press, 2005.

[4] M. Kuschel, B. Kryszak, W. Kalkner. Investigation of the "Non-linear" Dielectric Response of Water Tree-Aged XLPE Cables in the Time and Frequency Domain. IEEE International Conference on Conduction and Breakdown in Solid Dielectrics, Västeräs, Sweden: IEEE 1998: 85-88.

[5] Skjølberg J, Hvidsten S, Farmeo H. Experience from on-site condition assessment of XLPE MV cables. Electrical Insulation, 2006. Conference Record of the 2006 IEEE International Symposium on. IEEE, 2006: 432-435. 